\title{
Considerações sobre a velhice institucionalizada: memória social, cotidiano e ritmos de vida
}

Consideraciones sobre envejecimiento en los hogares de ancianos: memoria social, los ritmos diarios y hogares de ancianos

Considerations on aging in nursing homes: social memory, daily life and life rhythms

\section{Lucas Graeff}

Université Rene Descartes, Sorbonne, Paris, França.

\section{Resumo}

Apoiado na queda das taxas de mortalidade e nas novas técnicas de cuidado de si, o discurso gerontológico se interessa pela chamada "Terceira Idade" ou "Melhor Idade", onde a velhice não figura como um problema, mas como uma possibilidade de dispor de mais tempo livre e de melhores condições de vida. Porém, há aspectos tocando a população de idosos no Brasil que não dizem respeito ao lazer e aos cuidados com a saúde. A institucionalização é um deles. A fim de descobrir como vivem as pessoas idosas institucionalizadas e como elas significam o seu processo de envelhecimento, o presente trabalho apresenta os resultados de uma pesquisa etnográfica realizada em um asilo de Porto Alegre/RS. Através do ir e vir entre memória, cotidiano e ritmos de vida, os idosos estudados puderam refletir sobre seus tempos vividos no espaço asilar, propondo assim uma interpretação original da experiência de envelhecer no asilo.

Palavras-chave: Envelhecimento, Asilos, Memória social, Cotidiano, Ritmos de vida.

\section{Resumen}

Apoyado por la caída en las tasas de mortalidad y las nuevas técnicas de autocuidado, el discurso de la gerontología se ocupa de la llamada "tercera edad" o "Mejor Edad", donde la vejez no figura como un problema sino como una oportunidad para tener más tiempo libre y mejores condiciones de vida. Sin embargo, hay aspectos relacionados a la población anciana en Brasil que no se refieren a las prácticas de ocio y el autocuidado. La institucionalización es uno destes. Con el fin de averiguar cómo viven los ancianos institucionalizados y la manera en que ellos significan el envejecimiento, este trabajo presenta los resultados de un estudio 
etnográfico en un hogar de ancianos en Porto Alegre / RS. Mediante el movimiento de ir y venir entre la memoria, los ritmos diarios y hogares de ancianos, los ancianos estudiados podría reflexionar acerca de su vida en la institución, y por lo tanto ofrecer una interpretación original de los experiencia del el envejecimiento en el asilo.

Palabras clave: Envejecimiento, Hogares de ancianos, Memoria social, Vida cotidiana, Ritmos de la vida.

\begin{abstract}
Backed by the fall in mortality rates and new technologies of the self of self care, the discourse of gerontology is concerned with the so-called "Third Age " or "Best Age", where the old age does not figure as a problem but as an opportunity to have more free time and better living conditions. But there are aspects of the elderly population in Brazil that not concern free time and self care practices. Institutionalization is one. In order to analyze the conditions of life and the process of aging of the institution's residents, this paper presents the results of an ethnographic study in a nursing home located in Porto Alegre / RS. By going back and forth between memory, daily life and daily rhythms, the residents were able to think their lives in the daily life of the institution and therefore offer an original interpretation of the experience of aging in the asylum.
\end{abstract}

Keywords: Process of aging, Asylum, Social memory, Daily life, Life rhythms.

\title{
Introdução
}

Diversas áreas de pesquisa tomam o crescimento demográfico como justificativa para suas preocupações com a velhice. Segundo o "discurso gerontológico", por exemplo, a queda das taxas de mortalidade e a melhoria das condições de higiene fará com que um número cada vez maior de pessoas atinja a faixa dos 60 anos de vida. Na medida em que essa nova geração de idosos cuidar melhor de seus corpos e desfrutar das novidades das ciências médicas, novas atividades e padrões de consumo surgirão. Para essa geração, chamada de "Terceira Idade" ou "Melhor Idade", a velhice não figura como um problema, mas como uma possibilidade de dispor de mais tempo livre e de melhores condições de vida.

Porém, há outras formas de viver o envelhecimento no Brasil que têm dificuldade para se inscrever nos discursos que vinculam velhice, lazer e a práticas voltadas ao cuidado de si. O tema da 
institucionalização é um deles. Como vivem as pessoas idosas institucionalizadas? A partir de quais elementos significativos elas interpretam o seu processo de envelhecimento? O discurso gerontológico é preponderante em suas maneiras de viver a velhice? Quais referentes simbólicos o espaço institucional oferece ao idoso quando se trata de enquadrar essas formas alternativas de viver o processo de envelhecer?

A fim de responder a essas questões, o presente trabalho apresenta os resultados de uma pesquisa etnográfica realizada no Asilo Padre Cacique, em Porto Alegre/RS. Durante dezesseis meses, entre agosto de 2004 e dezembro de 2005, tomou-se por objeto o cotidiano asilar e suas interlocuções com a memória social das pessoas ali abrigadas. Através das técnicas de observação participante, diário de campo, descrição densa e entrevistas de profundidade, os idosos estudados puderam refletir sobre seus tempos vividos e sobre seu dia-a-dia no espaço asilar a partir de uma relação de reciprocidade durável com o pesquisador.

Ao narrar suas memórias, os idosos pesquisados articularam signos e estruturas de significado compartilhados, demonstrando como é possível elaborar alguns dos elementos trágicos da experiência de envelhecer: a ruptura com grupos e espaços sociais de referência; o afastamento ou a morte de parentes, amigos ou vizinhos; a perda da posição na hierarquia social, resultado de projetos sociais ou individuais mal sucedidos; as modificações físicas e o estranhamento do próprio corpo. Nesse ir e vir entre memória e cotidiano, uma interpretação original da experiência de envelhecer no asilo tomou forma, a saber, a consideração dos diferentes ritmos que cadenciam experiências cotidianas enquanto quadros sociais organizadores da experiência de envelhecer no asilo.

\section{O Cotidiano do Asilo: os Espaços e seus}

\section{Ritmos}

Entrar no Asilo Padre Cacique significa descobri-lo no contexto da cidade de Porto Alegre. Instalado na Avenida Padre Cacique, cujo nome é uma homenagem ao patriarca da instituição, o Padre Antonio Cacique de Barros, a instituição oferece-se ao passante através de sua imponente fachada, composta por uma grande escadaria e duas rampas que, em curva, abrem-se para a esquerda ou para direita, levando a uma grande porta em forma de arco. Ao alto, a inscrição "Asylo Padre Cacique" indica ao visitante que ele se encontra em frente a uma instituição cuja história é anterior a reforma ortográfica de $1911^{2}$. Nesses tempos, Asilo era rodeado pela paisagem 
campestre da Chácara do Cristal e ainda margeava o Guaíba ${ }^{3}$. Hoje, apesar de suas proporções monumentais - o prédio central possui aproximadamente $4 \mathrm{mil} \mathrm{m} 2$-, é possível passar em frente ao Asilo sem percebê-lo, já que o estádio de futebol José Pinheiro Borda, o Beira-Rio, ocupa boa parte do panorama local.

Uma vez ultrapassados a porta e o saguão de entrada, começa-se a descobrir como se dá o atendimento dos internos. No interior de uma única edificação, cerca de 150 residentes são abrigados e atendidos por uma equipe multidisciplinar composta por funcionários de enfermaria, voluntários e alguns profissionais especializados, como uma assistente social, um médico, uma nutricionista e estudantes de odontologia e enfermagem. Em 2005, segundo as informações fornecidas por Cristina Mesquita, assistente social do Asilo, aproximadamente $44 \%$ dos 150 residentes eram mantidos em enfermaria, dado a sua dependência física ou mental. Numa classificação intermediária, cerca de $29 \%$ se encontravam em regime de semidependência, necessitando de cuidados e atendimentos diários. Os outros 27\% independiam de atendimento especial e, muitas vezes, utilizavam as dependências do Asilo apenas como dormitório, realizando boa parte de suas atividades diárias fora da instituição.
Para que uma pessoa seja aceita no Asilo Padre Cacique, ela precisa passar por um processo de triagem e por um conjunto de procedimentos relativamente padronizados, que devem garantir uma entrada gradual no asilo. Uma das primeiras etapas nesse sentido é a realização de algumas entrevistas com a assistente social, cujo objetivo é o de descobrir, entre outras coisas, os motivos que trouxeram a pessoa ao Asilo. $\mathrm{O}$ candidato a uma vaga no Asilo deve passar igualmente por uma avaliação de saúde, visando identificar suas necessidades em termos de atendimento ambulatorial. Quanto ao ingresso propriamente dito, é de praxe apresentar o novo residente a um companheiro de quarto, o qual será responsável pela ambientação no local. Em geral, esse companheiro pertence a uma rede de relações específica. Portanto, ao ser apresentado a um companheiro de quarto, o novo asilado acaba definindo boa parte de suas futuras posições e relações sociais no espaço asilar.

Para o recém-chegado, o Asilo Padre Cacique oferece-se à visitação de maneira regulada. No saguão de entrada, é preciso negociar a passagem para as outras dependências da instituição. Na época do trabalho etnográfico que originou este artigo, o saguão contava com a presença emblemática de Jorge (nome fictício), um de meus principais interlocutores durante a 
pesquisa. Ex-garçom e mestre de cerimônias, ele fazia questão de questionar os visitantes e de apresentá-los à "diretoria", isto é, os funcionários que ele considerava como "os mais respeitados" da instituição.

Mas o cotidiano do Asilo não se resume ao que acontece no saguão de entrada. Ao contrário: durante a pesquisa etnográfica, quatro espaços em particular se afirmaram com lugares privilegiados de observação do que significa envelhecer no Asilo Padre Cacique. São eles as alas feminina e masculina, o refeitório e as enfermarias.

A ala feminina é composta por cinco dormitórios e duas enfermarias. À exceção dos três dormitórios localizados na parte dos fundos da instituição que podem ser acessados através da sala de televisão, todas as demais salas têm saída para os corredores que circundam o jardim. Nos corredores, há sofás, poltronas e cadeiras de rodas para uso geral. Em relação à ala masculina, a frequiência é menor e é mais raro encontrar idosas conversando nesses lugares, que têm caráter público e impessoal. As relações de sociabilidade costumam ocorrer nos quartos ou na sala de visitas, principalmente quando elas recebem a família ou conhecidos de fora do Asilo.

Caminhando pelos corredores da ala feminina, surgem oportunidades para ouvir narrativas sobre relações familiares, conflitos nos quartos, trabalho doméstico e atividades cotidianas no Asilo. Oscilando entre "histórias boas" e "histórias tristes", como elas me diziam, uma preocupação com os riscos vividos no cotidiano se destaca. As mulheres que entrevistei recorriam muitas vezes a histórias de quedas, doenças e morte - seja no contexto institucional ou fora dele. Falava-se, por exemplo, das violências da cidade vividas por familiares ou pela próprias idosas que ainda se aventuram fora dos muros da instituição.

Um outro ponto interessante das "boas" e "tristes" histórias que me foram narradas são os juízos de valor que as habitam. Quando uma pessoa adoece, cai ou se recupera de um drama pessoal ou familiar, um código moral específico rege as relações entre o/a protagonista da história, a narradora e seus ouvintes. Nele, a manutenção da honra e do respeito, a valorização do foro íntimo e o controle emocional são extremamente relevantes.

Segundo o teor das narrativas, a experiência de envelhecer das mulheres pesquisadas no Asilo Padre Cacique contribui ao estabelecimento de microprojetos de distinção social (Bourdieu, 1979; Velho, 2004). Na medida em que se sobrevive às "histórias tristes" e que se vive "boas histórias", é possível elaborar a luta contra a senilidade e se afirmar como 
alguém capaz de se "comportar adequadamente", isto é, segundo o código de valorização do foro íntimo e do controle emocional. É a "velhice como carreira", nas palavras de Guita Debert (1999), onde manifestações de raiva ou ciúme, a perda do controle sobre as emoções ou até mesmo falar mal - ou falar demais - da família podem ser índices de senilidade.

Completando a divisão por gênero do Asilo Padre Cacique, à direita da entrada da instituição encontra-se a ala masculina. Nos corredores, há certos sons que diferenciam esse lado em relação à ala feminina: são tosses, pigarros e conversas resmungadas sobre o frio - "que derruba o cara”. Não que o frio não afete ambas as alas do asilo: é a própria peculiaridade de habitação do espaço que define essa ambientação sonora. De maneira geral, os corredores do Asilo configuram-se como espaços públicos e impessoais, por oposição ao espaço privativo e íntimo do quarto. Porém, os homens habitam esse espaço diferentemente das mulheres. Eles costumam sentar-se em cadeiras dispostas ao longo dos corredores, mas passam boa parte de seu tempo calados. O jardim que fica em frente está sempre vazio. O silêncio é dominante, sendo rompido geralmente por tosses e pigarros. Certamente, quando um colega de asilo, um voluntário ou um funcionário passa por perto, uma saudação ou reclamação qualquer podem dar início a uma conversa mais longa. Mas, de maneira geral, a ambientação sonora dessa ala é bem menos permeada por conversas - como é o caso da ala feminina.

Quando o silêncio dos corredores da ala masculina é rompido por uma longa conversa ou discussão, um código moral que organiza as trocas verbais funda-se na honra, senilidade e respeito ${ }^{4}$. Ainda que o quarto seja lugar privilegiado de disputas e conflitos pessoais, é nos corredores que eles afirmam diferencialmente suas identidades e trajetórias sociais. Distinções que organizam hierarquias, definidas abertamente conforme os anos vividos, a força física, a sanidade mental, classe social e a proximidade com a direção do Asilo.

No caso da honra, o que está em questão é a virilidade. Força, ação, “dar no couro" são qualidades sistematicamente colocadas a prova pelos pares. Ao mesmo tempo - e é aqui que entra o respeito -, toda virilidade precisa ser justificada. Não basta afirmar que ainda se é capaz de "dar no couro": é preciso apresentar uma namorada ou sair a noite para ir num bar ou bordel. No caso da força, a corpulência conta antes de tudo. Mas não só ela: mesmo um homem considerado magro ou um pouco mais fraco pode "falar alto" e impor respeito. Se esse "falar alto" for acompanhado pela proximidade a alguma 
figura de prestígio - o diretor do asilo, por exemplo -, mais significativa é a "presença" (física, simbólica) do idoso frente a seus pares. Finalmente, a justificação da virilidade passa pelo respeito das normas internas da instituição. É preciso se mostrar valente, mas jamais ou quase nunca recorrer ao uso da força. Afinal, as agressões são proibidas no Asilo sob pena de expulsão.

Como pano de fundo desse código moral pela honra e o respeito, encontra-se o controle das emoções. Se é preciso justificar a virilidade, isso se explica também porque toda perda de controle pode ser avaliada pelos pares como uma perda prematura de sanidade. Assim considerado, o descontrole emocional pode se desdobrar em "brincadeiras de mau gosto". Diz-se de um colega que ele "se mija nas calças", que "mal consegue lembrar o nome dos filhos" ou ainda "que está sempre esperando a irmã que já morreu". Tais "brincadeiras de mau gosto" servem não apenas para desqualificar o colega senil, mas para afastar a própria ameaça simbólica da senilidade. Por outro lado, os "mais velhos" - isto é, que têm setenta anos ou mais -, costumam ser objeto de tolerância em relação ao controle das emoções. Eles também podem ser "respeitados" mesmo estando senis, porque os anos vividos justificam a condição física ou mental debilitada - servindo de destino provável a todos aqueles que alcançarem a mesma idade.

Terceiro espaço fundamental na compreensão do cotidiano do Asilo Padre Cacique, o refeitório localiza-se na ala masculina e abriga a função imediata de oferecer alimentação para todos os idosos que não estão acamados - uma vez que as enfermarias têm seu próprio sistema de nutrição. Porém, qualquer sugestão de evento extra-cotidiano a ser realizado no Asilo, como jogos ou festas, tem no refeitório a sua primeira opção de lugar. A explicação da equipe técnica é simples: dada a dificuldade de reunir os idosos, aproveita-se os momentos do dia em que eles se encontram agrupados em grande número.

Após cada refeição, abre-se um espaço potencial para sociabilidades, jogos e festas, que interrompem o dia-a-dia asilar e demarcam instantes e durações diferenciados. $\mathrm{O}$ espaçamento entre as atividades cotidianas proporciona as condições mínimas para a prática de lazeres no Asilo, como ocorreu na própria fundação da "Cultura do Lazer" (Dumazedier, 2004). Os lazeres, a sociabilidade e o lúdico organizam momentos privilegiados, extra-cotidianos, que liberam energia para a deliberação e formulação de projetos (Huizinga, 1973). Por essas interrupções e deliberações, a experiência de envelhecer no asilo percorre 
outros ritmos no refeitório, que contrastam com os tempos vividos nos quartos $\mathrm{e}$ corredores do Asilo.

As formas de sociabilidade têm uma orientação própria, que as diferencia de outras formações sociais: sua finalidade é a própria associação. Ainda que determinados elementos da vida social se façam presentes durante os momentos de sociabilidade, como a disputa por posições e distinções, eles não são decisivos para as livres associações entre grupos e indivíduos (Simmel, 1983). Tendo um fim em si mesmas, as formas de sociabilidade criam "mundos artificiais" que, no caso do Asilo Padre Cacique, se contrapõem ao "mundo da velhice" (Graeff, 2005, 2007, 2011).

Tal contraposição, contudo, não implica em uma mútua exclusão. A celebração de um noivado no refeitório demonstra como o caráter artificial das festas e sociabilidades repercute no "mundo da velhice", marcado também por fantasias, promessas e projetos sociais muitas vezes inverossímeis aos olhos dos colegas de Asilo, que procuram afirmar um senso de realidade. O cotidiano do Asilo Padre Cacique é marcado tanto por dramas, tragédias e fantasias quanto por momentos de festa, jogos e sociabilidade. Mesmo que as "fantasias" sejam um dos elementos fundamentais do "mundo da velhice", a oposição ao senso de realidade é um esforço de afirmar a sanidade mental e a consciência da condição de envelhecimento.

A experiência de envelhecer no Asilo Padre Cacique revela seus elementos mais dramáticos no espaço da enfermaria. Com efeito, pensar o cotidiano asilar significa colocar em contraste as imprevisibilidades do cotidiano, os limites impostos pelo próprio corpo e pelos corpos dos outros, os projetos de continuidade e as reflexões sobre o passado, o presente e o futuro. Descrever e interpretar tais imprevisibilidades, limites, projetos e reflexões no espaço da enfermaria implica em retomar a problemática da morte e da doença - fatos da existência, como diria Elias (2001) - no processo de envelhecimento. Porém, vale lembrar que, ao contrário dos hospitais, que dissecam a morte e a doença em pequenas etapas e afastam o moribundo de seus grupos de referência (Ariès, 1975), as enfermarias do Asilo fazem parte do espaço social mais amplo - e adoecer não implica necessariamente no rompimento com as relações afetivas estabelecidas com outros moradores.

Os técnicos e técnicas de enfermagem relatam que, se comparadas as experiências de quem trabalha em hospitais com as de quem trabalho no Asilo, o risco de sofrimento é maior nesse último caso, em razão da intensidade dos contatos 
cotidianos. Além dos casos de idosos que passam anos nas enfermarias, dada a fragilidade de suas condições, há aqueles que se curam, retornam aos seus quartos e continuam participando do dia-a-dia dos trabalhadores da enfermaria, que podem encontrá-los nos corredores do Asilo, no refeitório ou em atividades de lazer. Portanto, há sempre uma certeza velada de que, apesar das curas e recuperações, a morte e a doença participam e conformam os limites da experiência de envelhecer de todos os moradores do asilo.

\section{O Trabalho da Memória como}

\section{Elaboração do Presente: dois pontos de} vista sobre a velhice no asilo

Os diversos espaços asilares facilitam ou dificultam as formas de viver o processo de envelhecer em instituição. Com efeito, ritmos diferentes se impõem segundo os lugares e as práticas, estando intimamente relacionados às experiências de habitação dos espaços: se nas alas masculina e feminina o inverno e o verão dão o tom das relações, no refeitório, local privilegiado da sociabilidade, a sineta convida à reunião. Nas enfermarias, o tempo apresenta sua faceta inexorável: as mortes e doenças afirmam que os ritmos sucessivos do corpo não durarão para sempre, transformando-se até atingir a imobilidade.
A construção social da experiência de envelhecer no Asilo Padre Cacique se inscreve, portanto, entre os ritmos cotidianos e a finitude daqueles que ali residem. Mas como essas pessoas elaboram tudo isso? Quais os limites de sua produção dos sentidos do envelhecer numa instituição asilar? E como o discurso gerontológico se inscreve nessa produção? Os testemunhos de Carlos e Luísa oferecerão algumas respostas a essas questões. Tratam-se de dois pontos de vista diferentes, mas que se articulam a partir de um mesmo quadro social: o processo de asilamento e os elementos trágicos do processo de envelhecer, tais como o afastamento em relação a parentes, amigos ou vizinhos, a perda da posição na hierarquia social e o estranhamento do próprio corpo em virtude das transformações pelas quais este passou, de maneira súbita ou gradual, ao longo de sua existência.

Os pontos de vista sobre a velhice no Asilo Padre Cacique que serão apresentados aqui resultam de uma série de entrevistas e encontros informais com Carlos e Luísa e foram concebidos como um nexo significativo entre suas trajetórias de vida e o momento no qual eles se encontravam durante a pesquisa. Portanto, entende-se que esses pontos de vista são contextualizados e condicionados pelo Asilo, conforme suas regras, possibilidades 
e proibições. Dito de outra maneira, ao propor uma perspectiva sobre o seu processo de envelhecer em contexto asilar, o idoso institucionalizado está compartilhando seu cotidiano com o pesquisador e, ao mesmo tempo, demonstrando como é possível jogar com as normas e as necessidades impostas por sua experiência de asilo ${ }^{5}$.

Os roteiros das entrevistas foram semi-estruturados: para o primeiro encontro, propunha-se o seguinte: "gostaria que você me contasse um pouco de sua vida e sobre sua vinda para o Asilo Padre Cacique”. Essa sugestão procurava deixar em aberto a possibilidade de iniciar a narrativa pela situação atual de asilamento ou por histórias e dramas vividos no decorrer da trajetória de vida. O início, os pontos de amarração e o final da narrativa são dados fundamentais para compreender as formas pelas quais o sujeito trama sentidos sobre sua experiências vividas, produzindo um "artefato verbal", nas palavras de Pierre Bourdieu (1999). Para o segundo encontro, formulava-se um diagrama da trajetória de vida narrada na entrevista anterior, que serviria como ponto de partida para aprofundar alguns pontos da trajetória ou para pensar o cotidiano asilar. Procurou-se, assim, relacionar as experiências vividas à condição presente, marcada pelo processo de envelhecer no Asilo.
Carlos nasceu em 1930 na cidade de Caxias do Sul e morava no Asilo Padre Cacique desde maio de 2003. Estar no Asilo, para ele, era a garantia de sua sobrevivência. Após ter passado por um acidente doméstico, escorregando e batendo o joelho, e sofrendo uma isquemia cerebral, Carlos passou a utilizar uma cadeira de rodas para se locomover. Ele necessitava de cuidados médicos freqüentes - "eu to vivo graças a minha vinda pra cá”. Esses eventos, porém, não afetaram sua capacidade de reflexão. "Livreiro de profissão", como dizia, muitas vezes ouvi-o discorrer sobre Darwin, Engels e alguns outros autores ligados à temas de seu interesse, revelando uma longa trajetória de trabalho ligada à comercialização de livros.

Meus primeiros encontros com Carlos não foram muito animadores. Ele se interessou pela pesquisa antropológica e propôs discussões sobre sociologia, história e evolucionismo biológico. Era época da observação participante e eu perseguia um corpo de interesses que não envolviam tais discussões - na verdade, procurava estabelecer relações com informantes cuja condição atual de asilamento repercutia em suas narrativas de vida. Porém, procurei refletir metodologicamente sobre esse desconforto e acabei descobrindo em Carlos um 
importante interlocutor para refletir sobre o processo de envelhecer no Asilo.

Após a primeira entrevista, realizada em uma mesa do refeitório próxima à televisão, fomos obrigados a esperar três semanas, período no qual Carlos se recobrou de uma cirurgia. Terminada a recuperação, marcamos a segunda entrevista, que se passou na área do corredor em frente ao se quarto: é ali, principalmente no inverno, que Carlos faz suas siestas após as refeições, aproveitando o sol.

A segunda entrevista iniciou com relatos sobre sua juventude, em Caxias, onde viveu por pouco mais de vinte anos e militou em movimentos estudantis. $\mathrm{Na}$ década de 1950, duas razões o teriam levado para Porto Alegre: a "perseguição política" que ele estava sofrendo em sua cidade natal e o "amor platônico" que mantinha como uma moça da Capital. A militância, porém, suplantou o romance. Após dois anos, Carlos rompeu a relação que tinha se transformado em noivado considerando-a um possível "entrave a sua liberdade". Além disso, constituir família nunca foi uma aspiração: "comecei a analisar também os problemas de outros que eu conhecia, (...) meu pai e minha mãe, que casaram, viveram tantos anos e se separaram (...). Ia acontecer comigo a mesma coisa, então não adiantava, não queria casar".
Ao contrário de seu pai, que foi funcionário público, Carlos deu seguimento a um estilo de vida de formação cultural. Através da literatura, ele teve acesso a visões de mundo balizadas por valores "vanguardistas", "de esquerda" e "marxistas", circulou entre grupos "boêmios", que "trocavam a noite pelo dia" e descobriu que "livro é uma cachacinha que tu pega e te vicia”. O acesso a esses bens simbólicos não se deu através de uma trajetória universitária, própria de camadas médias, mas pelo ofício de livreiro. Para Carlos, comercializar livros foi a oportunidade de unir sua "curiosidade pela área humana" com remuneração, além de possibilitar circulação por grupos sociais que lhe seriam inacessíveis, como os movimentos estudantis.

Sobre sua vinda o Asilo, Carlos sempre a definiu como algo necessário, quiçá desejável. Sua condição de invalidez, somada às limitadas possibilidades financeiras, não lhe deixaram alternativa que não fosse a institucionalização. Porém, a escolha do Asilo Padre Cacique foi uma conquista baseada nas relações de amizade e reciprocidade estabelecidas no decorrer de sua trajetória social. Não se trata, portanto, de uma situação fortuita, mas do resultado do processo de negociação com a realidade. Como ele mesmo disse, foi preciso "aproveitar do momento". Aliás, 
em suas reflexões, foi ele quem melhor encadeou uma seqüência de acontecimentos que o levaram ao Asilo:

Eu morava no interior, na praia. Eu vim pra cá, uns dez dias depois eu machuquei o joelho. No banho. Tomando banho, o piso lisinho, lisinho, molhado e eu escorreguei, me fraturou o joelho. Ao fui pro Pronto Socorro, fiquei uns onze dias lá dentro do Pronto Socorro. Tinha uma série de coisas aqui que eu não sabia mais, tava dez anos fora de Porto Alegre. "então nós vamos te botar na Sociedade Emanuel" disseram. Foi a pior viagem que eu fiz até hoje (...). Passei quatro, cinco meses lá. Daí saí capengueando, vim pra encaminhar minha aposentadoria - que foi uma briga também - consegui e fui indo. Até que me deu uma isquemia cerebral e aí fui pra uma geriatria dum cara ali, que era bom... Mas eu tava sempre sentado na cama ou deitado, sentado ou deitado, fiquei uns quatro, cinco meses ali. E aí eu lutei pra vir pra cá. Um amigo meu, que teve esses dias aqui até, digo: “pô, fala lá, eu quero vir, dá um jeito de vir pra aqui mesmo, que aqui fica perto do centro" (...). A SPAAN eu não queria, lá eu tinha facilidade, mas não... Em último caso, iria na SPAAN, né? Aí pensei, mas tem um cara, o Ibsen Pinheiro, que me conhecia...aí o Ibsen Pinheiro trabalhava no Estado aqui, como assessor de imprensa (...). Aí o Ibsen na mesma hora pegou o telefone, telefonou pra cá, decerto falou com a Cristina ou com seu Júlio, não sei com quem. Uns dias depois me entrevistaram, aquela coisa toda, aí vim pra cá... Aí foi outra coisa, fui pra outro mundo, completamente diferente... Vim assim na época dizendo: "é o paraíso". O que me trouxe pra cá foi isso. Eu to vivo por aqui graças a minha vinda pra cá, isso eu tenho que dizer.

Tendo alcançado uma certa estabilidade em sua condição de saúde, Carlos retomou a atividade que havia the conferido status social diferenciado em sua trajetória. Desde 2003, quando chegou à instituição, vem contribuindo diretamente para a manutenção e expansão da biblioteca do Asilo - ainda que ela esteja localizada no subsolo, local de difícil acesso para quem necessita de cadeira de rodas para se locomover.

É no refeitório, porém, que Carlos costuma passar boa parte do seu tempo. Cinéfilo, ele localiza lembranças de infância para explicar seus gostos, contando que seu pai era sócio de uma empresa cinematográfica e ele podia assistir gratuitamente, várias vezes por semana, os filmes que a empresa financiava. Em Porto Alegre, chegou a trabalhar com cinema na década de 1960: "fiz várias amizades, como o Romeu Grimaldi, que era diretor do Bristol lá no Bom Fim. (...). Tinha mais o Gastal, que é o nome da outra sala, a P.F.Gastal. E outros tantos, que não me vêm na memória e que eu conheci."

No Asilo, as televisões, rádios e os jornais cumprem a importante função de 
mediar relações entre os moradores e o mundo exterior. As imagens comunicadas, acústicas e visuais, amenizam a experiência de ruptura simbólica com os grupos de referência. Para Carlos, elas servem ainda como uma ponte de ligação com os espaços afetivos da memória. Ao asseverar seu gosto por filmes, relacionando-o a lembranças de sua infância e juventude, ele está conformando marcos identitários e afirmando a continuidade de seu estilo de vida, apesar do asilamento e da velhice.

Conjugadas as dramaticidades da vinda para o Asilo e a disputa simbólica pela habitação do espaço do refeitório, Carlos investe suas motivações no cotidiano asilar. "Não dá pra lutar lá fora", diz, referindo-se ao não-lugar do velho no mercado de trabalho. Não havendo perspectiva de emprego, tampouco haverá projeto realizável de retornar aos espaços e grupos de referência ou da constituição de novos, tendo em vista os custos concretos do envelhecer. Em sua cadeira de rodas, Carlos reconhece que o asilamento não é um capítulo intermediário de sua trajetória social, mas constitui a etapa final dela: "O cara que vem pra cá, tem que ficar aqui o resto da vida. E é isso aí, mas o que que eu vou querer lutar lá fora? Não tenho condições de arrumar emprego, nem arrumo nada. (...). Tu vê só, eu tenho um amigo, ele é mecanógrafo, trabalhava com máquina de escrever. Até que um belo dia, os computadores chegaram e mataram a profissão completamente. (....). E o cara não teve tempo de se adaptar."

A morte social de uma profissão é sinal da vertiginosa transformação dos ritmos da vida contemporânea. Como seria possível para Carlos, ou para qualquer outro velho asilado, sobreviver a esses ritmos? É nessa reflexão sobre o tempo que ele inscreve a impossibilidade de ultrapassar o asilamento: "Então não tem nada mais pra gente construir, na realidade. Com a tecnologia que tá aí, vai te encurtando, cada vez mais o teu caminho. A vida mudou toda, né? Hoje tá tudo mudado... Emprego é só pra quem é jovem e tá estudando. Não dá pra tu te adaptar".

O caso de Luísa é bastante diferente do de Carlos. Nascida em 1931 no município de Mariana Pimentel, no Rio Grande do Sul, ela veio morar no Asilo no início de 2005. Fomos apresentados em março do mesmo ano, durante um dos encontros do grupo de trabalhos manuais. Desde então, quando me encontra, Luísa faz questão de me relatar as últimas notícias do Asilo e, por vezes, me conduz ao encontro de alguma "velhinha" que “está precisando conversar". Sempre procurando facilitar associações entre visitantes, funcionários e moradores do Asilo, ela foi uma das pessoas que melhor compreendeu a pesquisa: "é um trabalho 
que ele está fazendo para apresentar lá fora. Que ele tem que trabalhar com os idosos, conversar com eles, fotografar e tudo", como contou certa vez para o professor de dança.

As duas entrevistas foram realizadas na sala de visitas. Foi ali que Luísa me contou de sua trajetória de trabalhadora doméstica e fez questão de destacar os anos de serviços prestados a importantes famílias do Estado - "fui em quem criou aquelas crianças”, disse. Sempre envolvida em alguma atividade, nunca deixou de atualizar seus saberes práticos no cotidiano do Asilo: quando a entrevistei, ela disse já haver trabalhado na cozinha e na lavanderia e que poderia até limpar o seu quarto, mas "aqui tem essas funcionárias que fazem o serviço".

Recém-chegada no Asilo, Luísa já assumia posições morais claras sobre a instituição e sobre a velhice. A responsabilização do indivíduo por seu próprio bem-estar, próprio da “reprivatização da velhice" (Debert, 1999) faz parte dessas posições: Luísa falou-me inúmeras vezes das noções de "atividade", "animação" e "disposição", próprias ao discurso gerontológico. Ao jogar com tais categorias, Luísa não apenas inscrevia sua visão de mundo nas representações da Terceira Idade, mas afirmava uma identidade social a partir delas.
Essa Manuelinha aí. Hoje ela está no aniversário do filho. $\mathrm{O}$ filho dela, não sei se hoje completa 50 anos. Olha, tu não dizes a idade que ela tem. Essa aí é faca na bota. Essa trabalha na lavanderia, ela sai e faz as compras na rua. É uma pessoa ativa (...). A minha irmã, que eu cuidei, foi aos 92 anos. Mas, se ela ficava na cama! Essa hora ela estava lá vendo o movimento da estrada, da faixa. Quantos ônibus passavam. Ela queria ver movimento. É o meu caso: eu tive na cozinha até a hora da ginástica. Servi água para os velhinhos. Saí da ginástica e chegou a hora do almoço. Agora ajudei na louça, fui lá na roupa. Estendi umas roupinhas (...).Eu acho que esse é o viver, tu não achas?

Em seu cotidiano, Luísa procurava "manter-se ativa": promovia encontros entre voluntários e os "velhinhos" e trabalhava na cozinha, na enfermaria da Ala Feminina e na lavanderia do Asilo. Com efeito, ela parecia estar o tempo inteiro "performatizando" práticas associativas, de lazer e filantrópicas. Nesse sentido, é interessante notar o vínculo afetivo que ela estabeleceu junto à instituições católicas, como a PUC-RS ou o próprio Asilo Padre Cacique, sustentando suas ações em "valores católicos carismáticos" (Stiel, 2004) - ela relatou, por exemplo, suas experiências pessoais com o sagrado a partir de elementos mediadores, como o Padre Marcelo Rossi. 
Outro elemento significativo que explica as práticas sociais de Luísa no contexto asilar refere-se à lógica relacional do apadrinhamento. Pelo que foi possível identificar a partir das observações etnográficas e das entrevistas de profundidade, a noção de apadrinhamento que aparece na narrativa de Luísa é análoga àquela apresenta por Roberto Da Matta (1997): no Brasil, onde as noções de indivíduo e pessoa demarcam uma dinâmica bilateral, o apadrinhamento oferece um tratamento diferenciado em espaços sociais onde operam regras impessoais ou proporciona a passagem da condição de indivíduo para a de pessoa, posicionando-o na hierarquia social.

Quando Luísa narra sua vida e aponta a importância de seus patrões como "homens de poder", por exemplo, seu esforço é o de se inscrever positivamente no campo social. Falar de pessoas que trabalharam na Petrobrás ou na Rádio Difusora é uma maneira de se autoatribuir uma relevância social, como mostra o exemplo a seguir:

Eu tenho uma cunhada, mãe desse rapaz que está na Petrobrás. E as outras duas são minhas grandes amigas. Mas o pai delas era... O meu tinha falecido e ele ficou como um pai pra mim. De repente o homem deu derrame. Deu derrame, e aí a minha cunhada de Pelotas veio para cuidar (...).No dia que ele morreu, tinha na Rádio
Difusora "Um Novo Dia Começa Para $T i$ ”, aquele programa com Frei Renato. E foi lá que noticiaram a morte dele. Aí, na mesma hora que eu liguei e ela já me disse: "Nós não vamos velar em Guaíba. Vamos velar na casa dele" - que é ali onde é o sítio do meu irmão hoje. O genro era um dos da empresa Guayba. Dono da empresa Guayba. Um deles. Uma delas era casada, e depois ele morreu, a coitada é viúva. E disse: "Vai ter uns dez ônibus Guayba que vão levar o pessoal". E eu acho que foi uns trinta ônibus. Mas o homem era tão famoso, tão famoso. Para lá não precisou, todo mundo escutou a rádio já tava sabendo e foi lá.

O caráter fundamental dessas relações para Luísa se expressa no cotidiano asilar. Quando ela promove associações entre pessoas, assume a posição de porta-voz em atividades lúdicas e oferece sua força de trabalho para o cuidado com os "velhinhos", ela está reinventando a lógica do apadrinhamento no Asilo. Agora, é ela quem serve de referência na definição de relações de pertencimento e, por extensão, de posições mais ou menos valorizadas no espaço asilar. Ainda que essa autoridade não seja amplamente reconhecida, trata-se de um importante signo organizador do processo relacional entre identidade, memória e imaginação. É através dela que Luísa concretiza seus juízos sobre a instituição. 
Nesse contexto, o papel exercido por Luísa no Asilo Padre Cacique é bastante peculiar. Afirmando-se como tutora ou madrinha dos "velhinhos", ela exclui de sua autorepresentação os elementos simbólicos que caracterizam o estigma da velhice - a doença, a desesperança e a proximidade do fim da vida. Isso fica claro quando Luísa se utiliza da categoria "derrubar" para compreender não apenas as vicissitudes da velhice, mas para justificar o esvaziamento das atividades lúdicas e a perda da "animação" por parte dos "velhinhos".

Tá meio brabo pra reunir a turma da ginástica. Foram só doze hoje. Sempre iam trinta, trinta e oito, quarenta pessoas. Hoje foram só doze. Está tudo resfriado. Parecem que estão tudo desanimados. É a velhice que derruba essa gente. Eu não sei se tu não tens notado, que parece que não se vê velho na rua. Estão tudo na cama. Eu estou vendo isso. Seis meses estão fazendo essa semana que eu estou aqui. Eu cheguei aqui parece que eu via mais animação. Agora parece que está tudo, como é que eu vou te dizer? Parece que eles estão... Como é que eu vou te dizer? (...). É a velhice derrubando...

\section{Considerações Finais}

Os acontecimentos sociais que tomam lugar nas diversas dependências do Asilo Padre Cacique conformam os ritmos das lembranças e do envelhecimento de cada asilado. Sem romper com a lógica institucional pautada por normas, espaços coletivos e distanciamento em relação à trajetória social anterior, os residentes organizam novos quadros sociais, que podem estar pautados tanto por dramas e tragédias como por situações de sociabilidade e de solidariedade.

Por um lado, a densidade e a duração dos tempos vividos no Asilo Padre Cacique dependem dos ritmos apreendidos e elaborados no interior do asilo. As formas de habitar os espaços institucionais, assim como "trabalho da memória" (Bosi, 1987; Halbwachs, 1990) realizado em situação de entrevista, são expressões do esforço de consolidação da experiência que cada residente realiza. Por outro lado, alguns elementos característicos do discurso gerontológico se fazem igualmente presentes nesse esforço de consolidação. Como foi possível perceber a partir do exemplo de Luíza e de Carlos, o lazer e as práticas voltadas para o cuidado de si são amplamente valorizadas, seja nas narrativas ou no cotidiano asilar.

Mais precisamente, Luísa se mostrou com uma espécie de porta-voz de algumas idéias-valor próprias ao discurso gerontológico ao procurar interpretar as condições de vida no Asilo ou ao comentar as práticas de suas colegas de instituição. Participante ativa das atividades lúdicas 
(canto, dança, trabalhos manuais), ela ainda faz questão de se apresentar como cuidadora dos "velhinhos". Quanto a Carlos, seu depoimento corrobora a lógica de risco que está embutida no cuidado de si característico da "velhice bem sucedida"6. Como comentado anteriormente, o declínio físico não pode ser tomado como uma situação plástica a ser superada através de exercícios e boa alimentação. Ao contrário: em casos como o de Carlos, uma queda pode transformar completamente a experiência de envelhecer.

Como se explica o cruzamento entre ritmos asilares, quadros sociais e discurso gerontológico no caso do Asilo Padre Cacique? Em primeiro lugar, é preciso considerar que as imagens da velhice no Brasil vêm se transformando e, com elas, as práticas de cuidado em relação aos idosos. Desde o início da década de 1990, circula na mídia impressa e televisiva e nos meios acadêmicos e profissionais voltados ao envelhecimento uma série de idéias-valor ligadas ao discurso gerontológico. Ainda nesse período, foi promulgado o Estatuto do Idoso no Brasil, que vem servindo de instrumento de reivindicações políticas e para o próprio Estado, que se apóia na Lei para fiscalizar as instituições filantrópicas, religiosas e privadas de amparo à velhice e à Terceira Idade. O Asilo Padre Cacique se inscreve nesse contexto geral de reconstrução social da velhice e vem aplicando uma política de abertura onde o controle social dos residentes é cada vez menos despersonalizador: desde as mudanças nos critérios de seleção e nos horários de visitas, passando pelo convite à participação de familiares e voluntários no dia-a-dia e nas festas do Asilo, até as pequenas modificações nos quartos, cada vez menores, privados, proporcionando espaços de intimidade.

Em segundo lugar, os próprios residentes se mostraram capazes de refletir sobre suas práticas e suas condições de vida. Uma das hipóteses da pesquisa realizada no Asilo Padre Cacique é que o esforço sistemático de produção e interpretação de sentidos, possível em virtude da redução do controle social exercido no espaço asilar, permite a constituição de novas figurações sociais. Nesse sentido, as pressões exercidas pela instituição se tornariam cada vez menos necessárias uma vez que os próprios residentes são capazes de avaliar suas práticas e de cuidar de si mesmos.

Finalmente, é preciso incluir a participação de voluntários e profissionais na circulação do saber gerontológico no interior do Asilo Padre Cacique. Com efeito, as pessoas que se dispõem a trabalhar ou a prestar serviços voluntário numa instituição asilar são portadoras de um capital cultural atravessado pelas 
idéias-valor da gerontologia (Mazza e Lefevre, 2004). Além disso, os asilos são muitas vezes objeto de práticas reformadoras (Veras, 1997; Tomasini e Alves, 2007) e costumam servir como uma espécie de laboratório para estudos comparativos de capacidades funcionais e emocionais $^{7}$. A presença desses pesquisadores também contribui a circulação do discurso gerontológico no espaço asilar.

Em resumo, as idéias-valor de um discurso como o da geriatria e da gerontologia são capaze de ultrapassar os muros de uma instituição outrora definida como "total" (Goffman, 1974) e de permear os ritmos asilares e os pontos de vista sobre o processo de envelhecer em asilos. Espera-se que, ao contextualizar os moradores do Asilo Padre Cacique no quadro de seus dramas e de seu cotidiano, o presente trabalho venha a contribuir para evocar o caráter de construção social de algumas dessas idéias e valores - as quais não passam muitas vezes de pré-noções ligadas a representações da velhice enquanto problema social.

\section{Notas}

1 Por discurso gerontológico, entenda-se alguns pressupostos orientadores do discurso e da prática de geriatras e gerontólogos brasileiros que vêm se evidenciando em análises como as de Guita Debert e de Simoni Lahud Guedes (Debert, 1993; Guedes, 2000).

${ }^{2}$ Mais precisamente, o Asilo foi fundado em 1881, época na qual a velhice e a mendicidade eram confundidas e intoleradas em uma cidade que se propunha moderna e progressista. Nas palavras de Sandra Pesavento, “[...] um novo imaginário urbano se constCarlosu em torno da busca de uma cidade limpa, bonita e ordenada (...). Objeto de um discurso higienista, que se articulava a uma política moralizadora, as vivências e territórios dos pobres era tematizada como focos de criminalidade, prostituição e promiscuidade" (Pesavento, 1999, p. 58). Em Porto Alegre, o início do século XX foi marcado pela política social de subvenções do governo Borges de Medeiros, que contribui para o custeamento e continuidade das grandes instituições, como o Hospital Psiquiátrico São Pedro, fundado em 1884, e a Santa Casa de Misericórdia, fundada em 1826. Junto com o Asilo Padre Cacique, essas "instituições pias" tinham a finalidade de atender a indivíduos carentes e, no caso do Hospital Psiquiátrico, "loucos e alienados" (Guzinski, 1995).

${ }^{3} \mathrm{Na}$ década de 60, a área à frente do Asilo seria aterrada, dando espaço ao novo estádio de futebol do Sport Clube Internacional, o Beira-Rio. 
${ }^{4}$ Define-se honra como um sentimento de orgulho ligado a afirmação de determinadas normas sociais (Pitt-Rivers, 1979; Fonseca, 2000). O conceito de distinção é pensado a partir de Pierre Bourdieu (1996; 2001) enquanto posições ocupadas no espaço social do Asilo, que são constantemente definidas conforme o capital econômico e cultural dos indivíduos que participam e organizam esse espaço social. A distância entre as posições varia de acordo com as diferenças nos estilos de vida afirmados pelos velhos, seja em seu cotidiano no asilo, seja em suas trajetórias de vida narradas. Respeito, em Luiz Fernando Duarte (1987), é uma medida de avaliação dos outros própria das classes trabalhadoras urbanas, mas que se faz presente no espaço asilar. Assemelha-se, também, à noção de "orgulho pessoal" formulada por Cláudia Fonseca, enquanto um "esforço de enobrecer a própria imagem" (Fonseca, 2000, p.15).

${ }^{5}$ Para a realização das entrevistas, utilizouse o conceito de "trajetória social" elaborado por Alfred Schutz (Schutz, 1979), o que permitiu analisar como o ponto de vista atual sobre a condição de asilado se relaciona com as escolhas de vida, preferências e aspirações do entrevistado. $\mathrm{Na}$ medida em que a trajetória era narrada, foi possível compreender o "campo de possibilidades" - limites que permitem determinada trajetória singular em detrimento de outras possíveis (Velho, 2004). As entrevistas e histórias contadas pelos entrevistados configuram, agora, um conjunto de textos: trata-se de um narrador - o idoso institucionalizados $\quad-\quad$ contando $\mathrm{o}$ encadeamento entre o presente e o passado, entre suas escolhas, seus sucessos e fracassos.

6 “Ao se propor como objetivo a qualidade de vida dos idosos, numa velhice autonomizada como objeto, desenha-se o modelo que pode ser sintetizado na categoria "nativa" velhice bem-sucedida. $\mathrm{Na}$ expressão concisa de um dos mais atuantes membros da Sala de Espera, um senhor de 77 anos, torneiro mecânico aposentado: 'Há dois tipos de envelhecimento: o de caráter biológico e o essencialmente social. No biológico, quero que Deus me dê saúde e, para ter saúde, tenho que seguir as orientações médicas e ter uma vida normal, dentro dos meus limites. No social, fazer o possível para estar sempre atualizado. Ter contato com os colegas de grupo, estar bem com a minha família e com jovens, até chegar o meu dia", (GUEDES, Simoni L., Op. Cit., p. 77).

7 Como exemplos desses trabalhos, ver Menezes e Marucci, 2005; Félix e Souza, 2009; Araújo, 2007; Lucena et al, 2002 


\section{Referências}

Araújo, M. O. P. H.; Ceolim, M. F.(2007).

"Avaliação do grau de independência de idosos residentes em instituições de longa permanência". Revista da Escola de Enfermagem da USP, 41 (3) $378-385$.

Ariès, P. (1975). Western atitudes toward death: from the middle ages to the present. Londres: The Johns Hopkins University Press.

Berger, P.; Luckman, T. (1973). A construção social da realidade. Rio de Janeiro: Vozes.

Bosi, E. (1987). Memória e sociedade. Lembranças de velhos. São Paulo, Queiroz Ed. Ltda. e EDUSP.

Bourdieu, P. (1979). La distinction. Paris: Éditions de Minuit.

Bourdieu, P. (1996). A economia das trocas lingüísticas. São Paulo: Edusp.

Bourdieu, P. (1999). A profissão de sociólogo: preliminares epistemológicas. Petrópolis, Rio de Janeiro: Vozes.

Bourdieu, P. (2001). Razões práticas. 3 ed. Campinas, SP: Papirus.

Debert, G. G. (1999). A reinvenção da velhice: socialização e processos de reprivatização do envelhecimento. São Paulo: EDUSP, 1999.

Bourdieu, P. (2000). "O Discurso Gerontológico e as Novas Imagens do Envelhecimento". São Paulo em Perspectiva, 17 (4) 121-128.

Duarte, L. F. (1987). Pouca vergonha, muita vergonha: sexo e moralidade em um grupo de trabalhadores urbanos. IN: LOPES, J.S.L. (org.). Cultura e identidade operária. Rio de Janeiro: UFRJ/Proed.

Dumazedier, J. (1999). Sociologia empírica do lazer. 2 ed. São Paulo: Perspectiva.

Duarte, L. F. (2004). Lazer e cultura popular. 3 ed. São Paulo: Perspectiva.

Featherstone, M. (1994). "O curso da vida: corpo, cultura e o imaginário no processo de envelhecimento". Textos didáticos: Antropologia e Velhice. IFCH/Unicamp (13) 49-71.

Félix, L. N.; Souza, E. M. T. (2009). "Avaliação nutricional de idosos em uma instituição por diferentes instrumentos". Revista de Nutrição, 22 (4) 571-580.

Fonseca, C. (2000). Família, fofoca e honra. Porto Alegre: UFRGS

Graeff, L. (2006). O mundo da velhice e a cultura asilar: estudo antropológico sobre memória social e cotidiano de velhos no Asilo Padre Cacique em Porto Alegre. Dissertação de mestrado em Antropologia Social. Porto Alegre: UFRGS. 
Graeff, L. (2007). Instituições Totais e a questão asilar. Estudos Interdisciplinares sobre $\quad 0$ Envelhecimento (11) 7-25.

Graeff, L. (2011, março) Le monde de la vieillesse et la culture asilaire: vivre en maison de retraite à Porto Alegre, Brésil. Vieillissement de la population dans les pays du Sud: famille, conditions de vie, solidarités publiques et privées: État des lieux e perspectives. Trabalho apresentado no Colloque International de Meknès, 2011, Faculté des Sciences Juridiques, Économiques et Sociales, (1).

Guedes, S. L.. (2000). “A concepção sobre a família na Geriatria e na Gerontologia brasileiras: ecos dos dilemas da multidisciplinaridade". Revista Brasileira de Ciências Sociais, São Paulo, v. 15, n. 43, p. 69-82.

Guzinski, (1995). Política social para o idoso carente no governo Borges de Medeiros: 1898-1928. Dissertação de Mestrado em História. Porto Alegre: PUCRS.

Goffman, E. (1974). Manicômios, prisões e conventos. São Paulo: Perspectiva, 1974.

Goffman, E. (1979). A representação do eu na vida cotidiana. 10 ed. Petrópolis, RJ: Vozes.
Halbwachs, M. (1990). Memória coletiva. São Paulo: Vértice.

Huizinga, Johan (2004). Homo ludens. 5 ed. São Paulo: Perspectiva.

Lucena, N.M.G. et al. (2002.) “Análise da capacidade funcional em uma população geriátrica institucionalizada em João Pessoa". Fisioterapia Brasil, (3) 164-169.

Matta, R. (1997). Carnavais, malandros e heróis. 6 ed. Rio de Janeiro: Rocco.

Mazza, M. M. P. R.; Lefevre, F. (2004). "A instituição asilar segundo o cuidador familiar do idoso". Saúde e Sociedade. [online], 13 (3) 68-77.

Menezes, T. N.; Marucci, M. F. N. (2005). "Antropometria de idosos residentes em instituições geriátricas, Fortaleza, CE”. Revista de Saúde Pública, 39, (2) $169-175$

Pesavento, S. (1999). Memória de Porto Alegre. Porto Alegre: UFRGS.

Pitt-rivers, (1979). Antropologia del honor o politica de los sexos: ensayos de antropologia mediterranea. Barcelona: Critica.

Tomasini, S. L.; Alves, S. (2007). "Envelhecimento bem-sucedido e o ambiente das instituições de longa permanência”. Revista Brasileira de Ciências do Envelhecimento Humano, 4 (1) 89.

Simmel, G. (1983). "Sociabilidade: um exemplo de sociologia pura ou 
informal". IN: Moraes filho, E. social e bens culturais, atuando (org.). Simmel. São Paulo: Ática.

principalmente nos seguintes temas:

Steil, C. (2004). "Catolicismos e memória memória social, antropologia urbana, no Rio Grande do Sul". Debates do patrimônio cultural, envelhecimento e NER, 5, (5) Porto Alegre: patrimônio histórico.

IFCH/UFRGS. E-mail: lucasgraeff@gmail.com

Velho, G. (2004). Individualismo e cultura:

Notas para uma antropologia da sociedade contemporânea. 7 ed. Rio de Janeiro: Zahar.

Veras, R. (1997). “A reestruturação do abrigo cristo redentor: o macroasilo transformado em uma minicidade". Physis [online], 7 (2) 85-104.

Schutz, Alfred. "Ação no mundo da vida" (1979). IN: WAGNER, H.. Fenomenologia e relações sociais. Textos escolhidos de Alfred Schutz. Rio de Janeiro: Zahar, 15-42.

Lucas Graeff. Graduado em Psicologia pela Universidade Federal do Rio Grande do Sul (2004), mestrado em Antropologia Social pela Universidade Federal do Rio Grande do Sul (2006) e doutorado em Etnologia e Sociologia Comparada Université Rene Descartes, Paris V, Sorbonne (2010). Atualmente é professor pesquisador do Centro Universitário La Salle. Tem experiência na área de Antropologia, com ênfase em Memória 